\title{
Numerical Simulation of Multiphase Flow and Mixing Behavior in an Industrial Single Snorkel Refining Furnace: Effect of Bubble Expansion and Snorkel Immersion Depth
}

\author{
Weixing DAI, Guoguang CHENG, ${ }^{*}$ Shijian LI, Yu HUANG and Guolei ZHANG \\ State Key Laboratory of Advanced Metallurgy, University of Science and Technology Beijing, 30 Xueyuan Road, Haidian \\ District, Beijing, 100083 P. R. China.
}

(Received on May 9, 2019; accepted on June 28, 2019; J-STAGE Advance published date: August 28, 2019)

\begin{abstract}
A coupled mathematical model is used to simulate the multiphase flow in an industrial Single Snorkel Refining Furnace (SSRF). Based on the present model, the evolution characteristics of bubble size, density, and velocity are analysed during the long-distance rising process. The comparative studies indicate that the expansion of bubbles has an enormous impact on the circulation rate and free surface in the vacuum chamber. Furthermore, the effect of snorkel immersion depth (SID) on the circulation rate, mixing time, and fluid flow are investigated. The results indicate that the circulation rate decreases with the increase of SID, while the mixing time shows an uptrend with the increase of SID. Particularly, when the SID exceeds $0.4 \mathrm{~m}$, the scope of dead zone around the snorkel dramatically increases, which further decreases the flow velocity of slag layer in the ladle.
\end{abstract}

KEY WORDS: SSRF; bubble expansion; snorkel immersion depth; mixing time; circulation rate.

\section{Introduction}

Nowadays, as the increasing demands for ultra-low carbon steel, improving decarburization efficiency is becoming more and more important. The RH degasser has been widely applied and shown good performance in the production of ultra-low carbon steel. ${ }^{1,2)}$ However, the decarburization rate of $\mathrm{RH}$ obliviously decreases in the low carbon region $(<20$ $\mathrm{ppm})$, where the reaction rate at the free surface exposed to the vacuum is the most crucial. ${ }^{3,4)}$ To meet the higher decarburization rate, the Single Snorkel Refining Furnace (SSRF) and Revolutionary Degassing Activator (REDA) have been developed as a novel vacuum refining equipment in China and Japan, respectively. ${ }^{5-8)}$

As illustrated in Fig. 1, the long rising distance of bubbles is a marked feature for SSRF, much longer than that of other vacuum refining devices, such as RH reactor, VD, and VOD. Owing to the large injection depth and reduced pressure, a large bubble-activated surface area can be obtained at the vacuum free surface for SSRF, ${ }^{9,10}$ which allows the molten steel to realize high-efficiency removals of carbon, hydrogen, and nitrogen from molten steel.

Generally, it is accepted that the efficiency increases as the mixing time is shortened and the circulation rate is increased during the SSRF process. The circulation rate and mixing time mainly depend on the structural and the operational parameters in the vacuum reactor. Owing to the

* Corresponding author: E-mail: chengguoguang@metall.ustb.edu.cn DOI: https://doi.org/10.2355/isijinternational.ISIJINT-2019-280

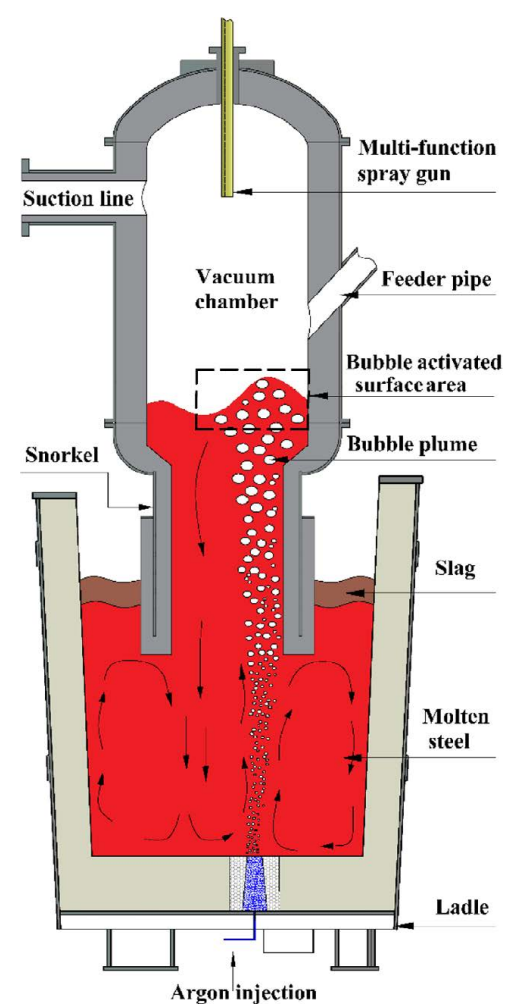

Fig. 1. The sketch diagram of the industrial SSRF. (Online version in color.)

limited application range of the SSRF, only a few researchers conducted the numerical simulation and water model to investigate the gas-liquid flow in SSRF or REDA during 
Table 1. Reported studies on the flow behaviors for SSRF or REDA.

\begin{tabular}{|c|c|c|c|c|c|c|c|c|c|c|}
\hline \multirow{2}{*}{ Method } & \multirow{2}{*}{ Author } & \multirow{2}{*}{ Scale } & \multirow{2}{*}{ Model } & \multirow{2}{*}{ Dimension } & \multirow{2}{*}{ Bubble expansion } & \multicolumn{5}{|c|}{ Investigated parameters } \\
\hline & & & & & & $Q$ & $h_{1}$ & $D_{l}$ & $r$ & $P_{v}$ \\
\hline \multirow{3}{*}{$\begin{array}{c}\text { CFD } \\
\text { modeling }\end{array}$} & Mondal et al. ${ }^{11)}$ & $175 \mathrm{t}$ & Euler-VOF & $2-\mathrm{D}$ & No & $\bullet$ & $\bullet$ & $\bullet$ & - & $\bullet$ \\
\hline & Yang et al..$^{12)}$ & $80 \mathrm{t}$ & Euler-Euler & $3-\mathrm{D}$ & No & $\bullet$ & $\bullet$ & $\bullet$ & $\bullet$ & \\
\hline & Geng et $a l .{ }^{13)}$ & $80 \mathrm{t}$ & Euler-Euler & $3-\mathrm{D}$ & No & $\bullet$ & & & - & \\
\hline \multirow{3}{*}{$\begin{array}{l}\text { Water } \\
\text { modeling }\end{array}$} & Aoki et al. ${ }^{14)}$ & $1 / 7$ & Air/water & - & - & $\bullet$ & & & & \\
\hline & Qin et al..$^{15)}$ & $1 / 4$ & $\mathrm{~N}_{2} /$ water & - & - & $\bullet$ & & & $\bullet$ & $\bullet$ \\
\hline & Rui et al. ${ }^{16)}$ & $1 / 5$ & Air/water & - & - & $\bullet$ & & $\bullet$ & & \\
\hline
\end{tabular}

past decades, ${ }^{11-16)}$ as summarized in Table 1. In the previous numerical simulations, a single-averaged size of ascending bubbles was usually employed. In practice, the long distance means that the rising bubbles suffer the tremendous changes of pressure and temperature, which further cause the huge volume expansion of bubble. Thus, the lack of consideration of bubble expansion cannot provide a rigorous description of the flow behaviors in SSRF. Although the water model can be utilized to realize the process of bubble expansion, the expansion ratio in the water system is much lower than that of the hot metal and can even be ignored. The importance of considering bubble expansion has been discussed by some researches. It was pointed that bubble expansion generates extra stirring energy for ladle mixing, ${ }^{17)}$ and increases the circulation rate for $\mathrm{RH}$ process. ${ }^{18)}$ However, the impact of bubble expansion in SSRF or REDA was rarely assessed in the previous studies.

Moreover, the snorkel immersion depth (SID) plays a key role for the circulation flow in SSRF system, but the effect of SID is seldom investigated in the reported studies as shown in Table 1. Mondal et al. ${ }^{11)}$ reported that circulate rate increases first and then decreases with the increase of SID, whereas Yang et $a l .{ }^{12)}$ pointed out that SID is not a sensitive parameter on circulation rate. All existing studies leave some uncertainties in regard to the effect mechanism of SID on multiphase flow. Therefore, more detailed analysis about the SID should be concerned.

In the present study, the VOF (volume of fraction)-DPM (discrete phase model) coupled mathematical model are established to reasonably describe the slag-steel-argon flow and mixing phenomena in SSRF. The main objective of the present study is to investigate the evolution characteristics of bubble size, density, and velocity during the long-distance rising process. The contribution of bubble expansion on circulation flow was evaluated for SSRF system. Furthermore, the effect of snorkel immersion depth (SID) on the circulation rate, mixing time, and flow field are investigated.

\section{Mathematical Model}

\subsection{Assumptions}

In this work, the following assumptions are made to simulate the multiphase flow in SSRF.

(a) The continuous phases are defined as Newtonian, viscous and incompressible.

(b) The system is assumed to be isothermal, the heat transfer between different phases is neglected.

(c) Spherical-cap bubbles are injected from the ladle bot- tom, the shape factor is set to $0.7,{ }^{18)}$ the equivalent diameter of bubble is assumed to be a diameter of a sphere with the equal volume, and the coalescence, collision and breakup of bubbles are ignored. ${ }^{19,20)}$

(d) The injected bubbles magnify turbulence in the bulk liquid. However, obtaining the bubble-induced turbulence is still an unsolved problem because the fraction of the induced energy converted into the liquid have different descriptions. ${ }^{20-22)}$ In the present model, bubble induced turbulence terms are ignored. Further improvements are required to consideration the effect of bubble induced turbulence and increased viscous dissipation.

(e) All the slag is placed into the ladle, there is no top slag in the vacuum chamber.

\subsection{Governing Equations}

The VOF model is employed to track the free surfaces by solving the continuity and momentum equation for the volume fraction of continuous phases. The DPM is used to describe motion of bubble trajectory. The trajectories are calculated in time and space according to Newton's 2nd Law, which is written in the Lagrangian reference frame. The chaotic effect of turbulence dispersion on bubble trajectories is considered using the random walk model in the continuous phases. The two-way turbulence coupling is used to realize the momentum exchange between the discrete phase and continuous phases. The basic governing equations of the coupled VOF-DPM model are summarized in Table 2.

\subsection{Turbulence Model}

The standard two-equation $k-\varepsilon$ model $^{23)}$ is used to model turbulence. Two equations, turbulence kinetic energy $(k)$ and the dissipation rate of turbulence kinetic energy $(\varepsilon)$, are solved to obtain the effective viscosity field, the corresponding equations are written as follows,

$$
\frac{\partial}{\partial t}\left(k \rho_{m}\right)+\nabla \cdot\left(\rho_{m} k \boldsymbol{u}_{m}\right)=\nabla\left[\left(\mu_{m}+\frac{\mu_{\mathrm{t}}}{\sigma_{k}}\right) \nabla k\right]+G_{k}-\rho_{m} \varepsilon
$$

$$
\begin{aligned}
& \frac{\partial}{\partial t}\left(\varepsilon \rho_{m}\right)+\nabla \cdot\left(\rho \varepsilon \boldsymbol{u}_{m}\right)= \\
& \nabla\left[\left(\mu_{m}+\frac{\mu_{t}}{\sigma_{\varepsilon}}\right) \nabla \varepsilon\right]+\frac{\varepsilon}{k}\left(C_{1 \varepsilon} G_{k}-C_{2 \varepsilon} \rho_{m} \varepsilon\right)
\end{aligned}
$$

$$
\mu_{t}=\rho_{m} C_{\mu} k^{2} / \varepsilon
$$


Table 2. Governing equations for the coupled VOF-DPM model.

\begin{tabular}{ll}
\hline \multicolumn{1}{c}{ Governing equations } & \multicolumn{1}{c}{ List of symbols } \\
\hline Governing equations for VOF & $\alpha_{i}$-volume fraction \\
Continuity: $\frac{1}{\rho_{i}}\left[\frac{\partial}{\partial t}\left(\alpha_{i} \rho_{i}\right)+\nabla \cdot\left(\alpha_{i} \rho_{i} \boldsymbol{u}_{m}\right)\right]=0$ & $\rho$-density of continuous phases, \\
Momentum: $\frac{\partial}{\partial t}\left(\rho_{m} \boldsymbol{u}_{m}\right)+\nabla \cdot\left(\rho_{m} \boldsymbol{u}_{m}\right)=-\nabla P+\nabla \cdot\left[\mu_{m}\left(\nabla \boldsymbol{u}_{m}+\nabla \boldsymbol{u}_{m}^{T}\right)\right]+$ & $\boldsymbol{u}_{m}$-velocity of mixture \\
$\qquad \rho_{m} g+\boldsymbol{F}_{b}+f_{\alpha}$ & $\rho_{m}, \mu_{m}$-volume average density and viscosity \\
Governing equations for DPM & $\boldsymbol{u}_{b, i}, d_{b, i}, d_{b, i}$-velocity, diameter and density of bubble \\
Bubble trajectory $\frac{d \boldsymbol{u}_{b, i}}{d t}=\boldsymbol{F}_{G, i}+\boldsymbol{F}_{B, i}+\boldsymbol{F}_{V M, i}+\boldsymbol{F}_{D, i}+\boldsymbol{F}_{P, i}$ & $C_{V M}$-virtual mass coefficient $(0.5)$ \\
Gravity and buoyancy force $\boldsymbol{F}_{G, i}+\boldsymbol{F}_{B, i}=\frac{\left(\rho_{b, i}-\rho_{m}\right)}{\rho_{b, i}} \cdot \boldsymbol{g}$ & $C_{D}$-drag coefficient ${ }^{18)}$ \\
Virtual mass force $\boldsymbol{F}_{V M, i}=C_{V M} \frac{\rho_{m}}{\rho_{b, i}} \frac{d}{d t}\left(\boldsymbol{u}_{m}-\boldsymbol{u}_{b, i}\right)$ & $R e_{b, i}$-Reynolds number of bubbles \\
Drag force $\boldsymbol{F}_{\boldsymbol{D}, i}=\frac{3 \mu_{m} C_{D} R e_{b, i}}{4 \rho_{b, i} d_{b, i}^{2}}\left(\boldsymbol{u}_{m}-\boldsymbol{u}_{b}\right)$ & $\dot{m}_{b}$-mass flow rate of bubbles \\
Pressure gradient force $\boldsymbol{F}_{P, i}=\frac{\rho_{m}}{\rho_{b, i}} \times \boldsymbol{u}_{b, i} \times \overrightarrow{\boldsymbol{u}}_{m}$ & $\Delta t$-time step \\
Two-way coupling $\boldsymbol{F}_{b}=-\sum_{i}^{N_{b, c e l l}}\left(\boldsymbol{F}_{V M, i}+\boldsymbol{F}_{D, i}+\boldsymbol{F}_{P, i}\right) \cdot \dot{m}_{b} \Delta t$ & $N_{b, c e l l}$-number of bubbles in a particular cell \\
Random walk model $\boldsymbol{u}_{b, i}{ }^{\prime}=\boldsymbol{u}_{b, i}+\xi \sqrt{2 k / 3}$ & $\Delta V_{c e l l}$-cell volume \\
$\boldsymbol{u}_{b, i}{ }^{\prime}$-fluctuating component of the bubble velocity \\
$\xi$-is a random number uniformly distributed between 0 and 1.
\end{tabular}

where $\mu_{t}$ is the turbulent viscosity, $G_{k}$ is the generation of turbulence kinetic energy due to the mean velocity gradients, $C_{1 \varepsilon}, C_{2 \varepsilon}, C_{\mu}, \sigma_{k}$ and $\sigma_{\varepsilon}$ are the empirical constants with values of $1.44,1.92,0.09,1.0$ and 1.3 , respectively.

\subsection{Bubble Size Model}

When bubbles are injected from the ladle bottom, the initial diameter of bubble is calculated by the following the experimental formula: ${ }^{17,24)}$

$$
d_{b, 0}=0.091\left(\frac{\sigma}{\rho_{l}}\right)^{0.5} u_{b, 0}^{0.44}
$$

where $u_{b, 0}$ is injection velocity of bubble at the exit of plug $(\mathrm{m} / \mathrm{s}), \sigma$ is the liquid steel-gas surface tension $(\mathrm{N} / \mathrm{m}), \rho_{l}$ is the density of the liquid steel $\left(\mathrm{kg} / \mathrm{m}^{3}\right)$.

To describe the bubble expansion due to density changes, the density $\left(\rho_{b, t}\right)$ and diameter $\left(d_{b, t}\right)$ of rising bubble are calculated at each time step according to the ideal gas law: ${ }^{18,20,25)}$

$$
\begin{gathered}
\rho_{b, 0}=\rho_{A r} \frac{\left(P_{V}+\rho_{l} g H\right) T_{0}}{P_{0} T_{l}} . . \\
\rho_{b, t}=\rho_{b, 0} \frac{P_{V}+\rho_{l} g(H-z)}{P_{V}+\rho_{l} g H} \\
d_{b, t}=d_{b, 0}\left(\frac{\rho_{b, 0}}{\rho_{b, t}}\right)^{1 / 3} \ldots \ldots . . .
\end{gathered}
$$

where $\rho_{b, 0}$ is the initial bubble density at ladle bottom $\left(\mathrm{kg} / \mathrm{m}^{3}\right), P_{V}$ is the pressure in vacuum chamber $(\mathrm{Pa}), H$ is the

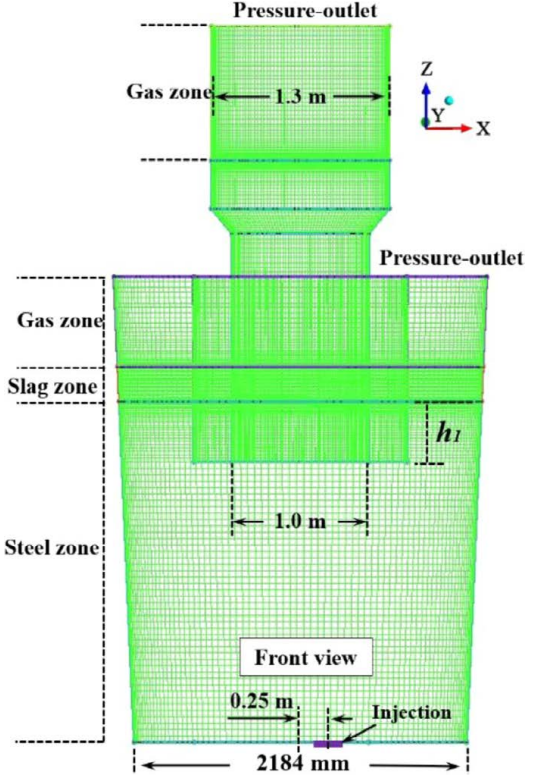

Fig. 2. Computational domain, mesh, and specified test positions. (Online version in color.)

liquid height along the vertical direction from ladle bottom to the free surface in vacuum chamber $(\mathrm{m}), z$ is the coordinate position of gas bubble in the vertical direction $(\mathrm{m}) . T_{0}$ and $P_{0}$ refer to the standard temperature and pressure (STP) of $273.15 \mathrm{~K}$ and $101325 \mathrm{~Pa} . \rho_{A r}$ is the bubble density at $\mathrm{STP}, T_{l}$ is the temperature of molten steel $1873 \mathrm{~K}$. The Eqs. (5)-(7) are compiled and loaded into the coupled model with the help of User-Defined functions (UDFs) in the Ansys software, which allows users to modify parameters as needed. At 
each time step, the updated $\rho_{b, t}$ and $d_{b, t}$ are returned to solve trajectories equations of the discrete bubble.

\subsection{Mesh and Boundary Conditions}

The major dimensions and mesh are shown in Fig. 2, and other parameters and material properties are listed in Table 3. The fluid domain is divided into four parts depending on initial fluid distribution at vacuum pressure. The local grid refinement was employed at the interfaces and region of bubble plume. The grid experiments were conducted to ensure that the simulated result is independent of grid number. The geometric model was meshed with five different grid density as listed in Table 4. Five cases were calculated with the identical gas flow rate $(100 \mathrm{NL} / \mathrm{min})$, snorkel immersion depth $(0.4 \mathrm{~m})$ and vacuum pressure $(2000 \mathrm{~Pa})$. The circulation rate of molten steel is selected as the indicator of the grid sensitivity experiments. It can be seen from Table 4 that the circulation rate is overestimated in Case1

Table 3. Dimensions and material properties of the $70 \mathrm{t}$ SSRF scaled water model.

\begin{tabular}{|c|c|c|}
\hline Parameters & Actual SSRF & Water model \\
\hline Diameter of ladle (up/down) & $2.45 / 2.184 \mathrm{~m}$ & $0.817 / 0.728 \mathrm{~m}$ \\
\hline Height of ladle & $3.06 \mathrm{~m}$ & $1.02 \mathrm{~m}$ \\
\hline $\begin{array}{l}\text { The weight and thickness of slag } \\
\text { layer in ladle }\end{array}$ & $\begin{array}{l}2.3 \text { ton, } \\
0.164 \mathrm{~m}\end{array}$ & - \\
\hline Diameter of plug & $0.10 \mathrm{~m}$ & $0.033 \mathrm{~m}$ \\
\hline Inner diameter of snorkel & $1.0 \mathrm{~m}$ & $0.333 \mathrm{~m}$ \\
\hline Inner diameter of vacuum chamber & $1.3 \mathrm{~m}$ & $0.433 \mathrm{~m}$ \\
\hline Length of snorkel & $1.6 \mathrm{~m}$ & $0.533 \mathrm{~m}$ \\
\hline Pressure of vacuum chamber & $2000 \mathrm{~Pa}$ & $96600 \mathrm{~Pa}$ \\
\hline Immersion depth of snorkel, $h_{1}$ & $0.2-0.7 \mathrm{~m}$ & $0.067-0.233 \mathrm{~m}$ \\
\hline $\begin{array}{l}\text { Interfacial tensions of molten } \\
\text { steel/air and water/air }\end{array}$ & $1.823 \mathrm{~N} / \mathrm{m}$ & $0.072 \mathrm{~N} / \mathrm{m}$ \\
\hline $\begin{array}{l}\text { Interfacial tension of molten } \\
\text { steel/slag }\end{array}$ & $1.15 \mathrm{~N} / \mathrm{m}$ & - \\
\hline Interfacial tensions of slag/air & $0.58 \mathrm{~N} / \mathrm{m}$ & - \\
\hline Density of molten steel/water & $7020 \mathrm{~kg} / \mathrm{m}^{3}$ & $998.2 \mathrm{~kg} / \mathrm{m}^{3}$ \\
\hline Density of slag & $3500 \mathrm{~kg} / \mathrm{m}^{3}$ & - \\
\hline Density of top air & $0.5 \mathrm{~kg} / \mathrm{m}^{3}$ & $1.25 \mathrm{~kg} / \mathrm{m}^{3}$ \\
\hline $\begin{array}{l}\text { Density of injection argon/air } \\
\text { at } 300 \mathrm{~K}, 0.1 \mathrm{Mpa}\end{array}$ & $1.623 \mathrm{~kg} / \mathrm{m}^{3}$ & $1.25 \mathrm{~kg} / \mathrm{m}^{3}$ \\
\hline Viscosity of molten steel or water & $0.0055 \mathrm{~Pa} \cdot \mathrm{s}$ & $8.5 \times 10^{-4} \mathrm{~Pa} \cdot \mathrm{s}$ \\
\hline Viscosity of slag & $0.05 \mathrm{~Pa} \cdot \mathrm{s}$ & - \\
\hline Viscosity of top air & $8.9 \times 10^{-5} \mathrm{~Pa} \cdot \mathrm{s}$ & $1.8 \times 10^{-5} \mathrm{~Pa} \cdot \mathrm{s}$ \\
\hline
\end{tabular}

and Case 2 because the low grid density is employed. After the total number of grids is higher than 579904 (Case 3), the circulation rate remains approximately constant. It means the total number of grids in Case 3 is sufficiently fine for obtaining reliable grid-independent results. The wall of the ladle, snorkel, and vacuum chamber were considered as no-slip wall function. The pressure-outlet boundary condition was adopted on the top surface the vacuum chamber and ladle. The rising bubbles disappear at the gas-liquid interface where the volume fraction of air is more than 0.5 .

\subsection{Computational Procedure}

The computational fluid dynamics software ANSYSFluent $^{\circledR} 17.0$ was used combining with UDFs to solve the multiphase flow. Figure 3 shows the solution procedure of the current model. The PISO scheme was used for the pressure-velocity coupling. ${ }^{25)}$ The time step was 0.001 second. After initialization, the transient simulation was run until a quasi-steady state was reached, then the species equation was activated until the tracer content was reached a 95\% level of homogeneity. All computations were performed on a Windows 10 PC with Intel $3.4 \mathrm{GHz}$ and $32 \mathrm{~GB}$ RAM.

\subsection{Definition of Circulation Rate and Mixing Time}

The circulation rate of SSRF is defined as the mass exchanging rate of steel between ladle and snorkel. As shown in Fig. 4(a), the cross section at the exit of snorkel is selected as the test surface $(\mathrm{S})$ to calculate the circulation rate. Since the upflow and downflow coexist in the snorkel, the surface-S is divided into two parts ( $\mathrm{S}-\mathrm{u}$ and $\mathrm{S}-\mathrm{d}$ ) according to the positive and negative of vertical steel velocity, corresponding the area occupied by the upflow and downflow, respectively. The mass flow rate through the specified area is computed as follows: ${ }^{19)}$

$$
M=\sum_{i=1}^{n} \rho_{l} \cdot u_{i}^{z} \cdot A_{i}
$$

where $n$ is the mesh number at the surface, $A_{i}$ is projected area of cell at the surface, $u_{i}^{z}$ is the vertical velocity of steel.

The mass flow rate is extracted when the quasi-steady state flow is reached. Two criteria are used to assess whether "quasi-steady state" is reached in SSRF: (i) the net mass flow rate of steel on the surface-S is close to zero because of mass conservation. Besides that, for mass flow rate of upflow and downflow $\left(M_{u p}, M_{\text {down }}\right)$, their values keep relative stable. (ii) the local flow velocity of steel in ladle reaches stability. Figure 4(b) shows the variation of monitored values with time. The predicted net flux shows a dramatical oscillation at first,

Table 4. Grid number and quality, as well as the predicted circulation rate.

\begin{tabular}{|c|c|c|c|c|c|c|c|c|c|}
\hline \multirow[b]{2}{*}{ Cases } & \multicolumn{5}{|c|}{ Grid number } & \multicolumn{3}{|c|}{ Grid quality } & \multirow[b]{2}{*}{$\begin{array}{c}\text { Circulation } \\
\text { Rate, kg/s }\end{array}$} \\
\hline & Total & Gas zone1 & Gas zone2 & Steel zone & Slag zone & MOQ & MOS & MAR & \\
\hline Case1 & 372539 & 285037 & 33745 & 41847 & 11910 & $5.70 \mathrm{E}-01$ & $4.30 \mathrm{E}-01$ & $1.13 \mathrm{E}+01$ & 882.3 \\
\hline Case2 & 465341 & 346971 & 37176 & 64155 & 17039 & $5.88 \mathrm{E}-01$ & 4.12E-01 & $9.66 \mathrm{E}+00$ & 863.6 \\
\hline Case3 & 579904 & 427649 & 52171 & 78496 & 21588 & $6.05 \mathrm{E}-01$ & $3.95 \mathrm{E}-01$ & $8.81 \mathrm{E}+00$ & 855.4 \\
\hline Case4 & 678828 & 505992 & 56700 & 88836 & 27300 & $6.05 \mathrm{E}-01$ & $3.95 \mathrm{E}-01$ & $9.52 \mathrm{E}+00$ & 858.1 \\
\hline Case 5 & 876559 & 653838 & 74307 & 114856 & 33558 & $6.07 \mathrm{E}-01$ & 3.93E-01 & $1.50 \mathrm{E}+01$ & 856.5 \\
\hline
\end{tabular}




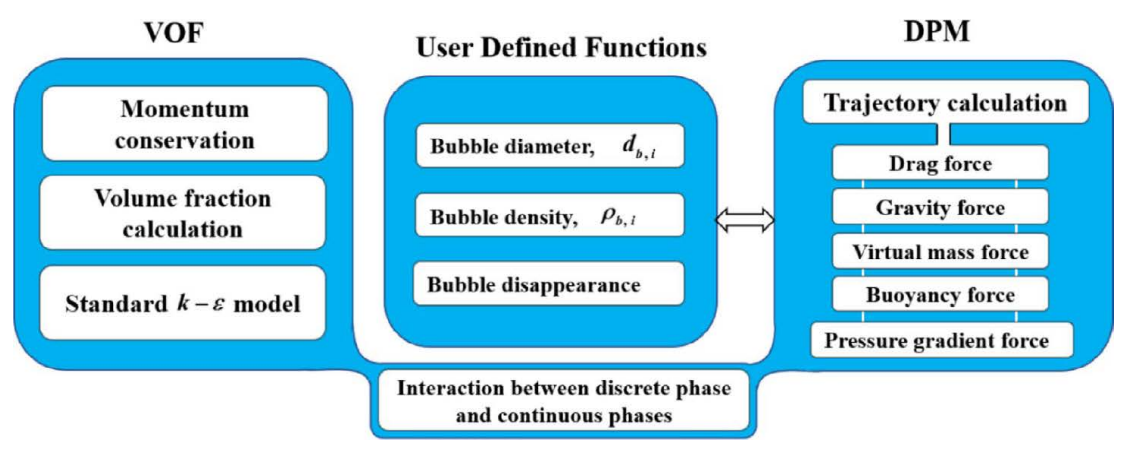

Fig. 3. The solution schematic of the present mathematical model. (Online version in color.)

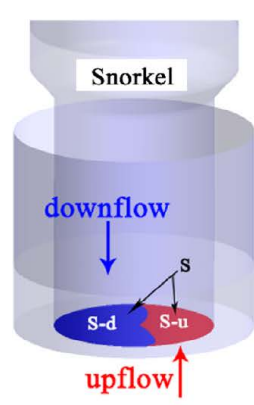

(a)

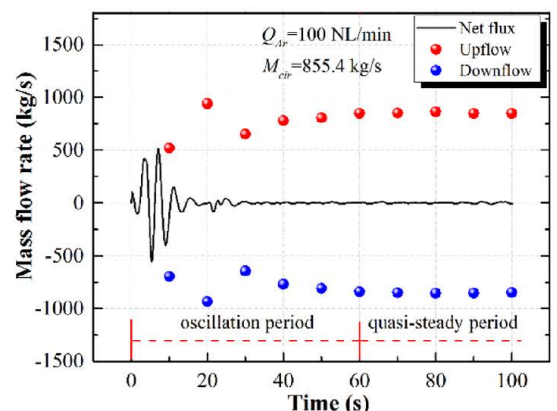

(b)

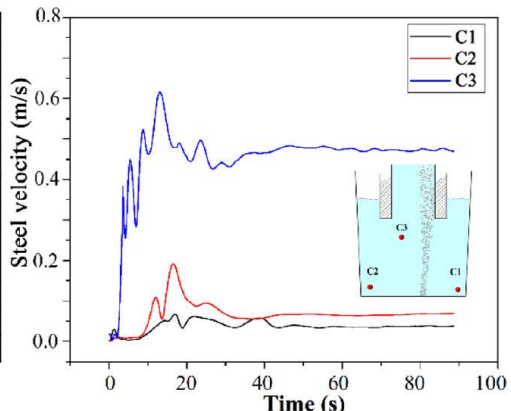

(c)

Fig. 4. (a) the schematic of test surface for circulation rate calculation, (b) the variation of monitored mass flow rate with time, (c) the variation of monitored steel velocity with time. (Online version in color.)

but the amplitude gradually decreases with computational time until close to zero (after $30 \mathrm{~s}$ ). Because of constantly changing of area for S-u and S-d with time, $M_{u p}$ and $M_{\text {down }}$ cannot be monitored in real time, thus, the area of S-u and S-d are extracted every ten seconds, the corresponding mass flow rate is calculated according to the Ep. (8). It can be seen that $M_{u p}$ and $M_{\text {down }}$ keep stability after $60 \mathrm{~s}$. Figure 4(c) shows the variation of monitored steel velocity with time, the velocity also keeps stability after $60 \mathrm{~s}$. Therefore, the quasi-steady state is achieved after $60 \mathrm{~s}$ based on these two judgments. Furthermore, the stable values of $M_{u p}$ and $M_{\text {down }}$ are used to calculate the circulation rate following below equation:

$$
M_{c i r}=\frac{\left|M_{u p}\right|+\left|M_{\text {down }}\right|}{2}
$$

The mixing time is calculated by solving species transport equation:

$$
\frac{\partial}{\partial t}\left(\rho_{m} C\right)+\nabla \cdot\left(\boldsymbol{u}_{m} \rho_{m} C\right)=\nabla \cdot\left[\frac{\mu_{m}+\mu_{t}}{S c}\left(\frac{\partial C}{\partial x_{i}}\right)\right] \ldots
$$

where $C$ is the tracer concentration, and $S c$ is the turbulent Schmidt number which is set to $0.7 .^{20)}$ The $95 \%$ mixing time is quantified as all monitoring values within \pm 5 percent of final concentration $\left(C_{\infty}\right)$.

\section{Results and Discussions}

\subsection{Effect of Bubble Expansion}

During the SSRF process, the increasing area of vacuum free surface effectively promotes decarburization. ${ }^{2}$ However, the characteristics of the free surface in SSRF are seldom mentioned in the previous literatures.

Figure 5 shows the effect of bubble expansion on free
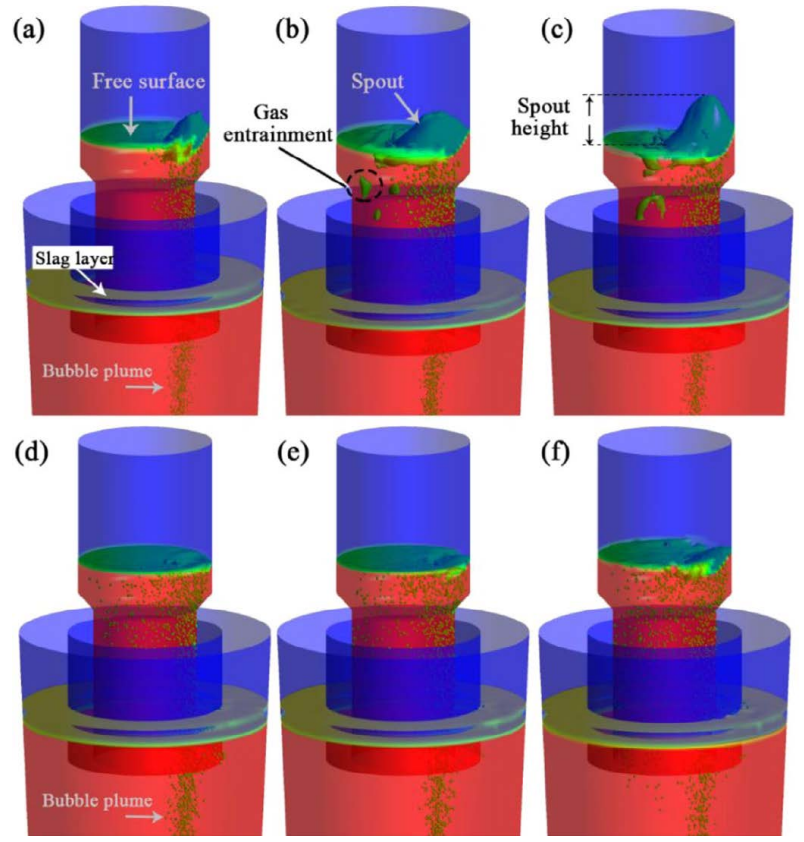

Fig. 5. The distribution of free surface and discrete bubbles under different gas flow rates with considering bubble expansion: (a) $100 \mathrm{NL} / \mathrm{min}$, (b) $200 \mathrm{NL} / \mathrm{min}$, (c) $400 \mathrm{NL} / \mathrm{min}$; and without considering expansion, (d) $100 \mathrm{NL} / \mathrm{min}$, (e) 200 $\mathrm{NL} / \mathrm{min}$, (f) $400 \mathrm{NL} / \mathrm{min}$. (Online version in color.)

surface in the vacuum chamber under different argon flow rates. When the bubble expansion is considered, the rise of bubble plume generates a raised spout above the vacuum free surface. It can be found that the increasing gas flow rate increases the height of spout, and liquid level fluctuation becomes more drastic, and increases area of free surface. However, the fluctuation is much weaker as the expansion of bubbles is ignored. 
Figure 6 displays the effect of bubble expansion on bubble diameter and vertical velocity. For the expanded bubble, the bubble size increases as it rises from ladle bottom to the vacuum chamber. In the ladle segment, the growth rate of bubble diameter is about 1.34 times, while the bubble diameter rapidly increases as the rising height exceeds the ladle free surface, especially approaching the vacuum free surface. In fact, for expanded bubble, the buoyancy of bubble increases with increasing diameter. Thus, the acceleration of bubble motion is continuously increased during the rising process. For unexpanded bubble, the diameter remains constant as small as the initial state, the bubble vertical velocity is slightly reduced as it close to the vacuum free surface. This phenomenon was also observed by Castillejos et al. $^{26)}$ in air-water system, where the expansion of bubbles can be neglected due to the low hydraulic head. It was pointed out that bubble rise velocity decreases near the bath surface because the direction of liquid flow is changed from upward to rapidly outward. Therefore, the motion of unexpanded bubble is easily influenced by changed flow direction of liquid because of its small size and low rising velocity. Moreover, the motion of argon bubbles can also be observed directly from the bubble distribution as presented in Figs. 5(d)-5(f), where scattered bubble is presented below the vacuum free surface, and rising bubbles are dispersed by change of liquid flow direction. However, for the expanded condition, the bubble plume is not easily dispersed because of its high rising velocity, as presented in Figs. 5(a)-5(c).

Figure 7 shows the effect of bubble expansion on local steel velocity. When the bubble expansion is considered, the steel velocity is obliviously enhanced in the snorkel. The expanded bubble increases the drag force and virtual force performing on the liquid steel, and further transfers more kinetic energy into the liquid steel. Figure 8 indicates that the circulation rate is increased with increase of argon flow rate, but after a certain flow rate, it becomes saturated. Figure 8 also show that the expanded bubble contributes more circulation rate than that of unexpanded bubble. Consequently, the expansion of bubbles should be considered in order to reasonably simulate the fluid flow in the industrial SSRF.

Additionally, with the increase of argon flow rate, the gas entrainment appears below the vacuum free surface as shown in Figs. 5(b) and 5(c). In fact, the gas entrainment phenomenon is beneficial to increase the activated gas/ steel interface in the vacuum chamber, which accordingly improves refining efficiency of degassing and decarburization. The formation mechanism of gas entrainment has been clarified by Satpathy et $a .^{27)}$ This type of entrainment occurs when two local conditions are available: (i) the liquid rises above the mean free surface forming a local hump, (ii) there is a high interfacial velocity of falling liquid from hump. The interaction between the falling liquid and the free

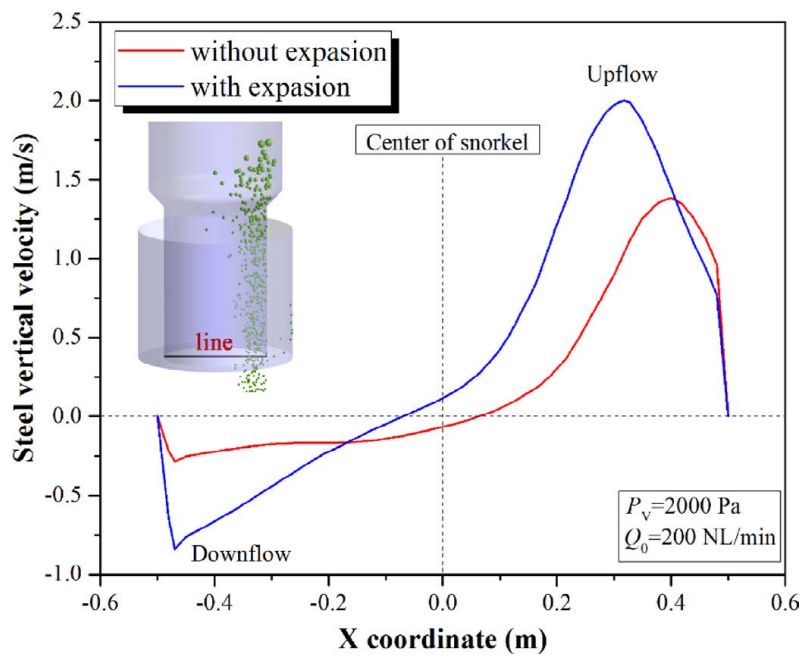

Fig. 7. The effect of bubble expansion on flow velocity of steel. (Online version in color.)

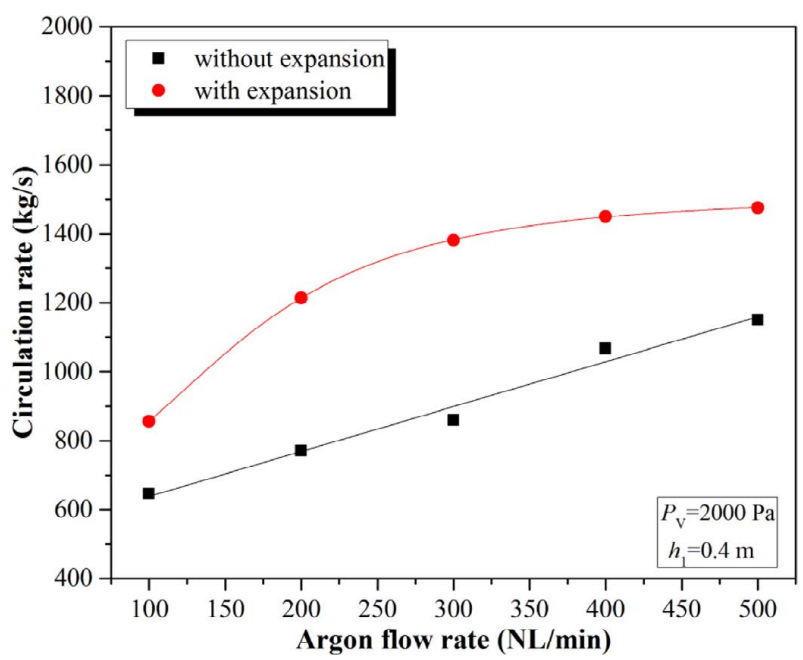

Fig. 8. The effect of bubble expansion on circulation rate. (Online version in color.)

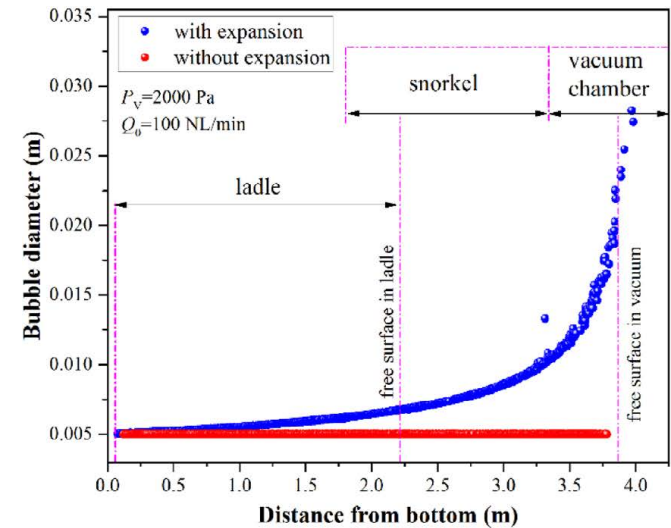

(a)

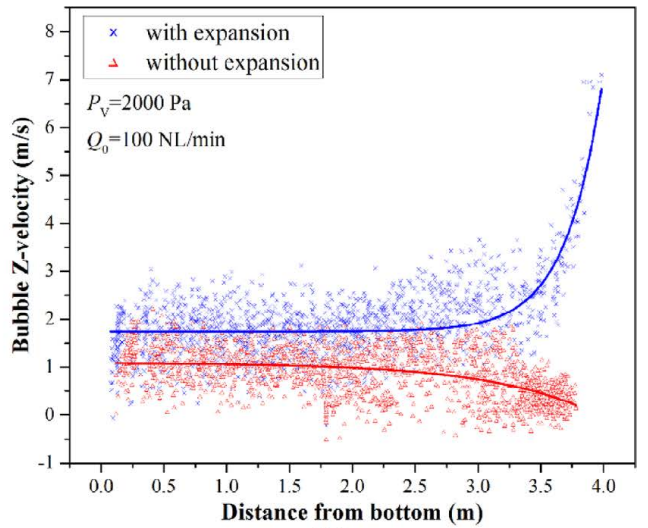

(b)

Fig. 6. The effect of expansion on local velocity of molten steel (a) diameter, (b) vertical velocity. (Online version in color.) 
surface causes entrapment of gas. In the vacuum chamber, the bubbles expansion and increasing argon flow rate cause the larger height of spout and higher interfacial velocity, thus gas entrainment is easily induced.

\subsection{Effect of Snorkel Immersion Depth}

The snorkel immersion depth (SID) is a significant operating parameter during the SSRF refining process. The effect of SID on circulation rate, mixing time and flow filed characteristics are investigated in this section. Six different SIDs from 0.2 to $0.7 \mathrm{~m}$ are employed, the argon flow rate $\left(Q_{0}\right)$ and vacuum pressure $\left(P_{V}\right)$ are kept $100 \mathrm{NL} / \mathrm{min}$ and $2000 \mathrm{~Pa}$, respectively. Other parameters are also remained constant as mentioned in Table 3.

\subsubsection{Circulation Rate}

Figure 9 shows the circulation rate as a function of SID. The circulation rate decreases with the increase of SID, and it is reduced about $50 \mathrm{~kg} / \mathrm{s}$ for every $0.1 \mathrm{~m}$ increase in SID. Seshadri et al. $^{28)}$ reported that the circulation rate is evaluated based on the energy balance, and dominated by the circulation path and stirring energy. The circulation path in SSRF can be illustrated as Fig. 10(a). The molten steel in ladle is lifted into the vacuum chamber along the right

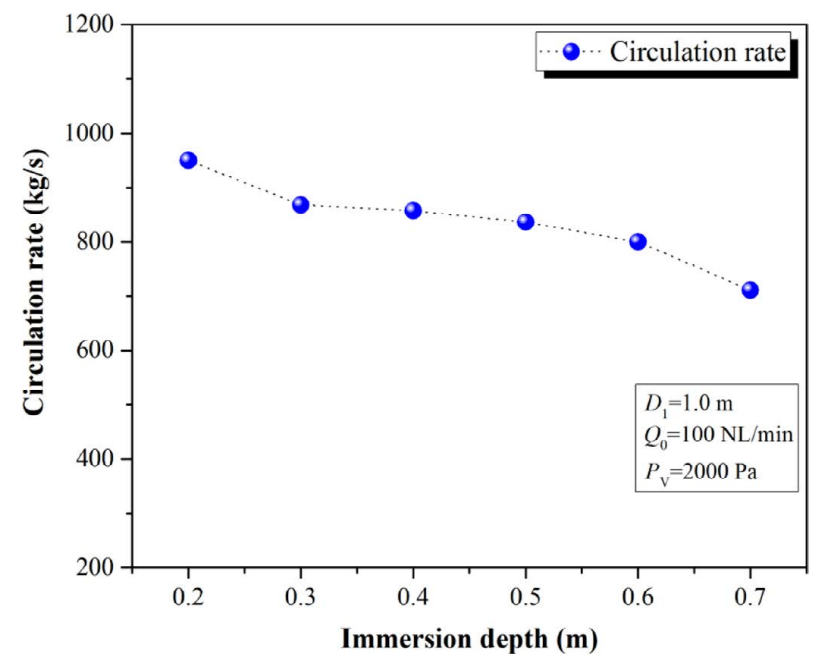

Fig. 9. The effect of immersion depth on circulation rate. (Online version in color.) wall of snorkel by rising plume, then returns into the ladle along the left wall of snorkel. As depicted in Fig. 10(b), the rising plume provides the stirring energy for circulation process, while a part of stirring energy is dissipated by the drastic viscosity friction between flowing steel and static snorkel wall, as well as the internal viscosity friction between upflow and downflow. Furthermore, Fig. 10(b) indicates that with the increase of SID, the total height $\left(H_{1}\right)$ of plume rising in the liquid steel is almost identical, while the wall height $\left(\mathrm{H}_{2}\right)$ submerged by molten steel is increased. It implies that with the increase of SID, the input stirring energy remains almost constant for circulation flow, but the circulation path of liquid steel in the snorkel and vacuum chamber is obviously increased, which further increases energy dissipation for circulation flow. As a result, the circulation rate is declined.

Figure 11 shows comparison of velocity distribution at the $\mathrm{Y}=0 \mathrm{~m}$ plane and test surface under different SIDs. Clearly, the velocity distribution of upflow is almost identical for different SIDs, but the velocity distribution of downflow is changed apparently. The maximum value of velocity appears near the left wall of snorkel, and a downtrend of downflow velocity is presented from the near wall region to the center of snorkel because of drastic viscous friction with conversed upflow. Meanwhile, the velocity of downflow near the wall region is also reduced at the vertical direction on account of wall friction. With the increase of SID, the velocity of downflow is further decreased in the snorkel due to the increasing circulation path and increasing energy dissipations. Accordingly, the velocity of downflow is decreased at the test surface.

\subsubsection{Mixing Time}

Several investigations have reported that the measured mixing time is affected by the locations of monitoring point and tracer addition. ${ }^{29,30)}$ Generally, the tracer is added in active region of bath, such as the spout eye, and the monitoring points are placed in the dead zone. However, the location of dead zone in SSRF is seldom clarified in the previous literatures. Therefore, it is vital to employ monitoring points as much as possible with the purpose of detailed mixing assessment. The locations of the seventeen monitoring points and tracer addition are depicted in Fig. 12.

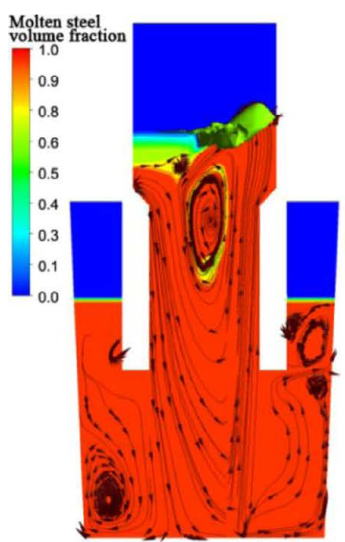

(a)

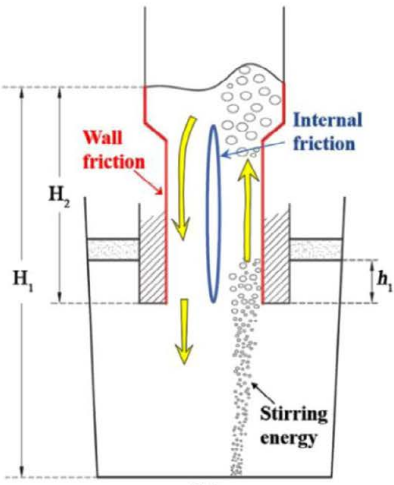

(b)

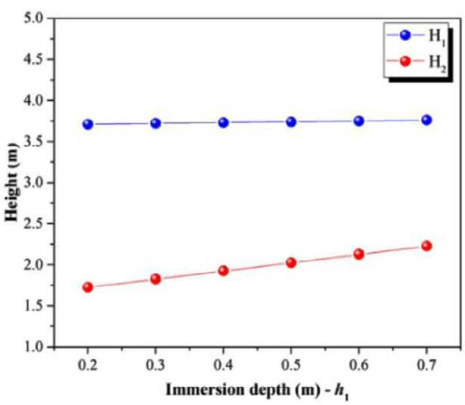

(c)

Fig. 10. (a) liquid phase distribution and streamline distribution at the $\mathrm{Y}=0$ plane, (b) the schematic of main energy consumption for circulation process in snorkel, (c) the effect of SID on the height of free surface and height of wall submerged by liquid steel. (Online version in color.) 


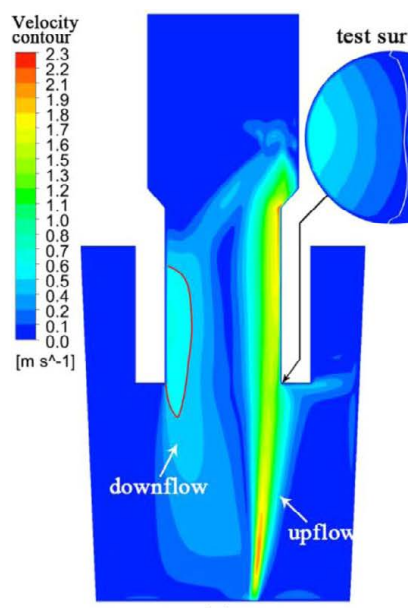

(a)

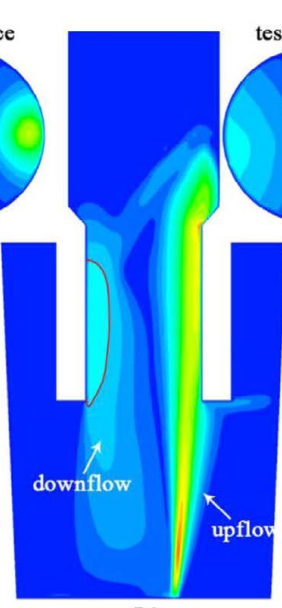

(b)

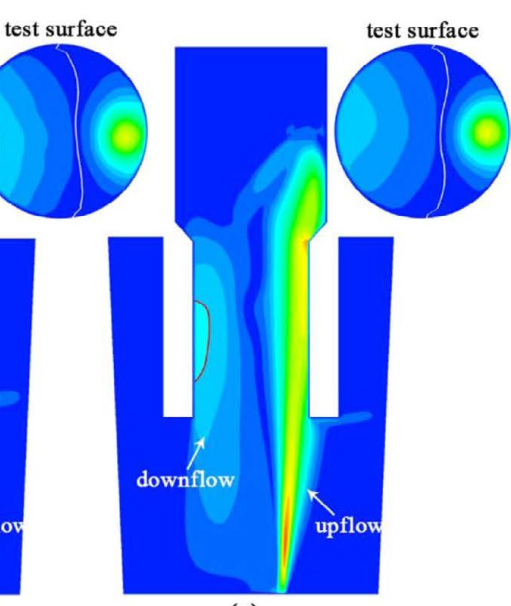

(c)

Fig. 11. The comparsion of velocity distribution at the $\mathrm{Y}=0 \mathrm{~m}$ plane and the test surface for different SIDs: (a) $0.2 \mathrm{~m}$, (b) $0.5 \mathrm{~m}$, (b) $0.7 \mathrm{~m}$. (Online version in color.)

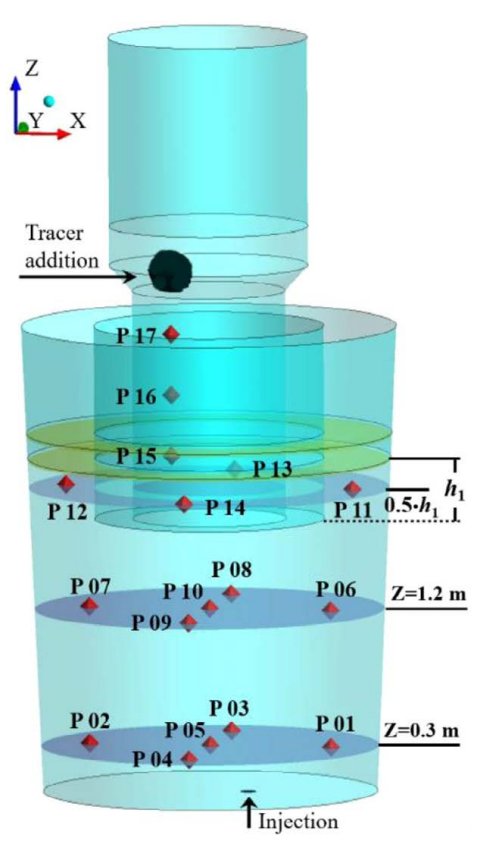

Fig. 12. Location of the trace addition and monitoring points for the mixing time measurement. (Online version in color.)

Figure 13 shows typical curves of dimensionless tracer concentration with time to achieve $95 \%$ mixing efficiency. The local mixing time highly depends on monitored location, and complete mixing time moderately increases from 209.4 $\mathrm{s}$ to $271.6 \mathrm{~s}$ as the SID is increased from 0.2 to $0.4 \mathrm{~m}$, then rapidly rises to $1021.4 \mathrm{~s}$ when the SID is increased to $0.7 \mathrm{~m}$. Furthermore, it is found that the mixing efficiency of whole bath is mainly determined by local mixing time monitored at P12, and its trend is always behind other monitoring points. This result implies that there is an evident dead zone near the P12. Besides that, it is observed that the variation trend of concentration at P13, P14, and P7 increase with the increasing SID. Apart from these stagnation points (P12-P14, P7), the trend and convergence time of the rest keep relative stable with the increase of SID. This result further indicates that there may be a continuous dead zone covering these stagnation points because their positions are close to each other around the snorkel as shown in Fig. 12. In addition, increasing depth may further worsen the flow of the dead zone.
It is well known that the local mixing time is closely related to local flow field. For further analysis of the flow field, the turbulent kinetic energy distribution of liquid steel is shown in Fig. 14 under different SIDs. Clearly, the region of low turbulent kinetic energy always appears at the top left corner of bath and periphery of snorkel, and the scope of dead zone is increased with increase of SID. This phenomenon is accordance with the tendency of local mixing time as shown in Fig. 13.

\subsubsection{Flow Field}

Figure 15 displays the streamlines distribution of steel and iso-surface of steel velocity $(0.25 \mathrm{~m} / \mathrm{s})$ under different SIDs. The streamlines show a symmetrical flow pattern along the $\mathrm{Y}=0$ plane because of the symmetric furnace structure. With the increase of SID, some similar flow characteristics can be found. For the downflow, it first impinges to the bottom of ladle, then flows along the ladle bottom, and climbs against the ladle wall. As a result, some recirculation eddies are formed at the bottom-side corner. It should be noted that these eddies cover the entire bottom of the ladle. As far as the individual is concerned, these eddies are in favor of the stirring and mixing for bottom liquid steel. Figure 15 also indicates that a part of upflow flows out of snorkel, then enters to the upper right-corner of bath. After a few turns, it flows away along the snorkel wall. It seems that this part of upflow plays an important role in promoting stirring around the snorkel.

However, at the periphery of snorkel, the flow pattern is changed as the SID is more than $0.4 \mathrm{~m}$. As shown in Fig. 16(a), when the SID is equal or less than $0.4 \mathrm{~m}$, two horizontal streams (1 and 2) are formed around the snorkel, then flow from P11 to P12 along the interspace between the snorkel and ladle. Subsequently, they collide with each other near the P12 because of symmetric flow distribution. In fact, the collision would cause attenuation of the flow velocity of melt. After the collision near the P12, a small part of steel can still be sucked into the inside of ladle by the high-speed downflow, but the influence of this suction is limited due to the obstruction of snorkel. When the SID is more than $0.4 \mathrm{~m}$, as shown in Fig. 16(b), the streams (1 and 2) flow obliquely from P11 to the interior of ladle, instead of flowing toward P12. Consequently, a large-scale flow dead 

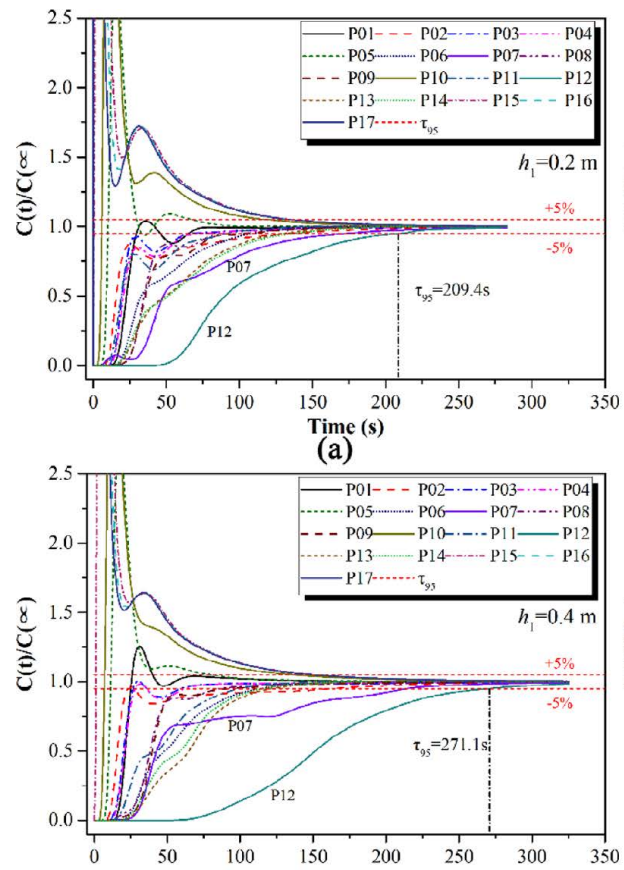

(c)

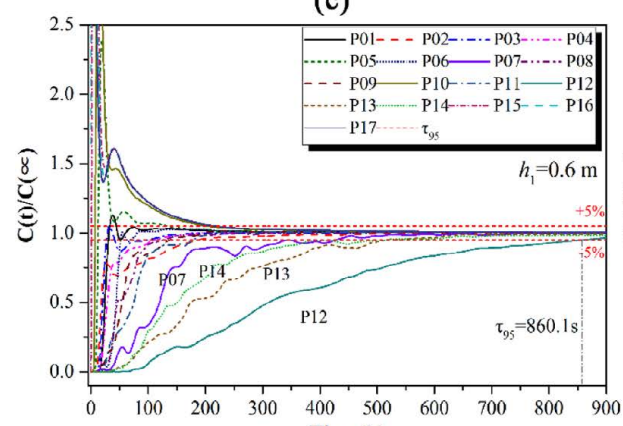

(e)

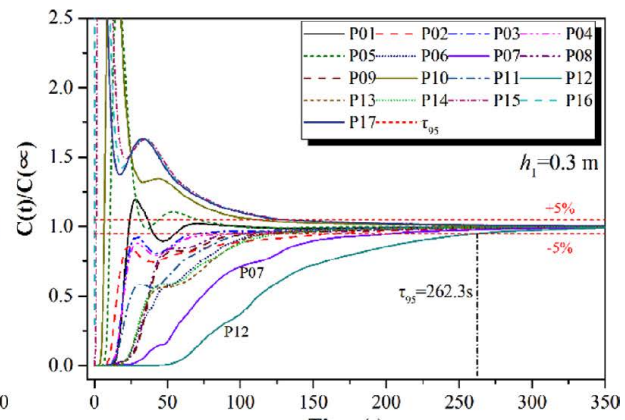

(b)

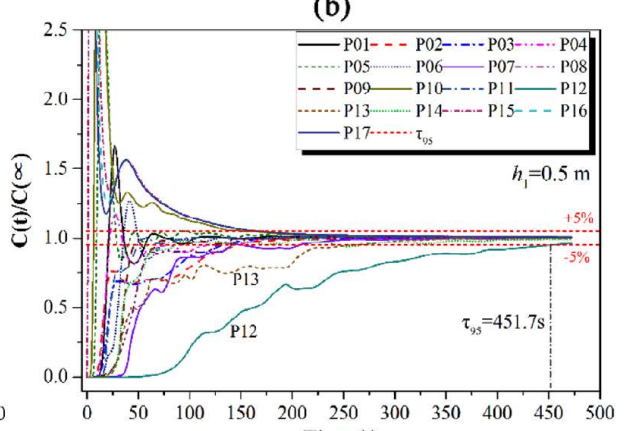

(d)

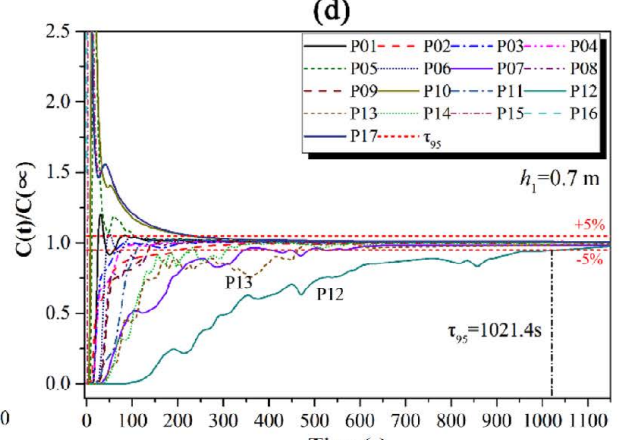

(f)

Fig. 13. Typical curves of dimensionless tracer concentration with time for different SIDs: (a) $0.2 \mathrm{~m}$, (b) $0.3 \mathrm{~m}$, (c) 0.4 $\mathrm{m}$, (d) $0.5 \mathrm{~m}$, (e) $0.6 \mathrm{~m}$, (f) $0.7 \mathrm{~m}$. (Online version in color.)

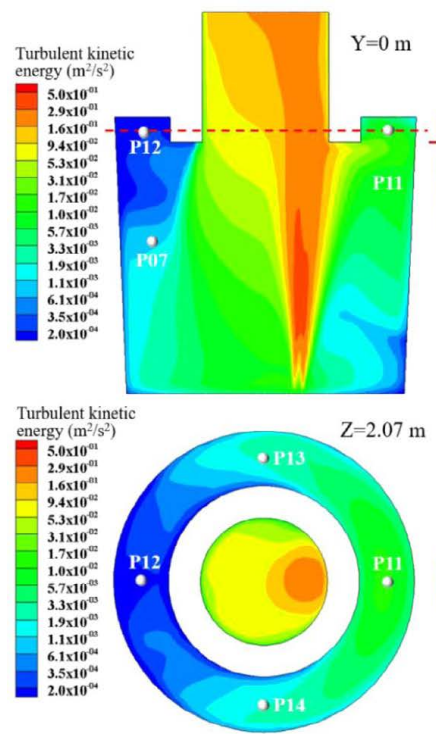

(a)

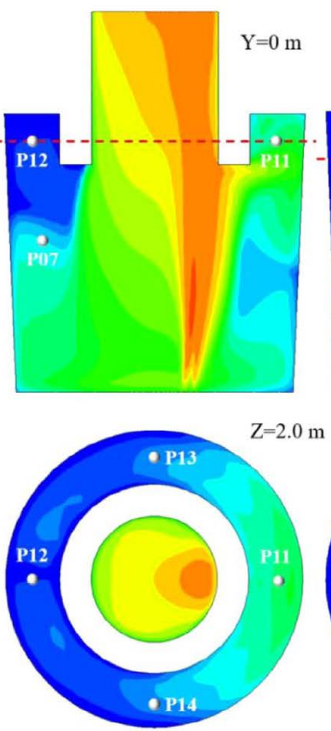

(b)
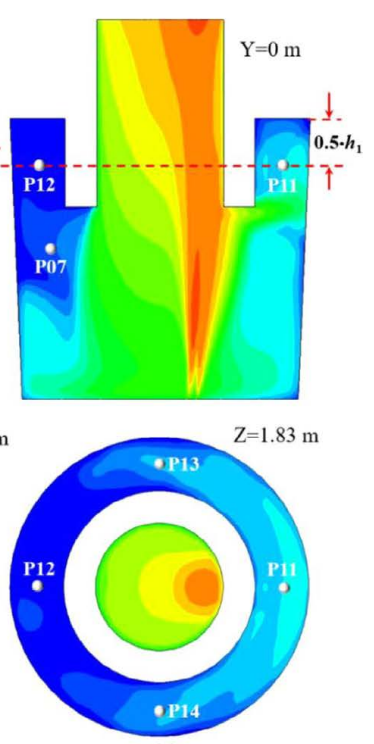

(c)

Fig. 14. Turbulent kinetic energy distribution of molten steel at the $\mathrm{Y}=0 \mathrm{~m}$ plane and $\mathrm{XY}$ plane for different SIDs: (a) $0.2 \mathrm{~m}$, (b) $0.4 \mathrm{~m}$, (c) $0.7 \mathrm{~m}$. (Online version in color.)

zone is formed around the snorkel.

Furthermore, the cold experiments also were performed to demonstrate the flow pattern in the air-water system of
SSRF. A cold model was established with $1 / 3$ scale ratio considering geometric and dynamic similarity criteria. The main structure parameters and operating conditions of cold 
model are listed in Table 3. Dynamic similarity was computed using the following expression:

$$
Q_{m}=\lambda^{n} Q_{\mathrm{fs}}
$$

where $\lambda$ is the geometrical scale factor, $Q_{m}$ and $Q_{\mathrm{fs}}$ represent gas flow rate of cold model and full scale system, respectively; and " $n$ " is an exponent with a value of 2.5. This value has been reported by Kim et al. ${ }^{31)}$ and Mazumdar. ${ }^{32)}$ The $100 \mathrm{ml}$ ink solution was poured into vacuum chamber as color tracer, and the front view of bath was captured by a video camera. ${ }^{33)}$

Figure 17 illustrated the flow pattern in the ladle by the spread of ink under different SIDs $(0.067,0.166$, and $0.233 \mathrm{~m}$, corresponding $0.2,0.5$, and $0.7 \mathrm{~m}$ in the melt). For the case of $0.067 \mathrm{~m}$, the ink is quickly dispersed to the whole bath within $32 \mathrm{~s}$. However, with the increasing SID, the dispersion time of the ink is extended to around $50 \mathrm{~s}$ due to the existence of the dead zone. Besides, it is also found in Fig. 17 that the impinging depth $\left(h_{d}\right)$ of downflow in the ladle is shortened with the increasing SID at the

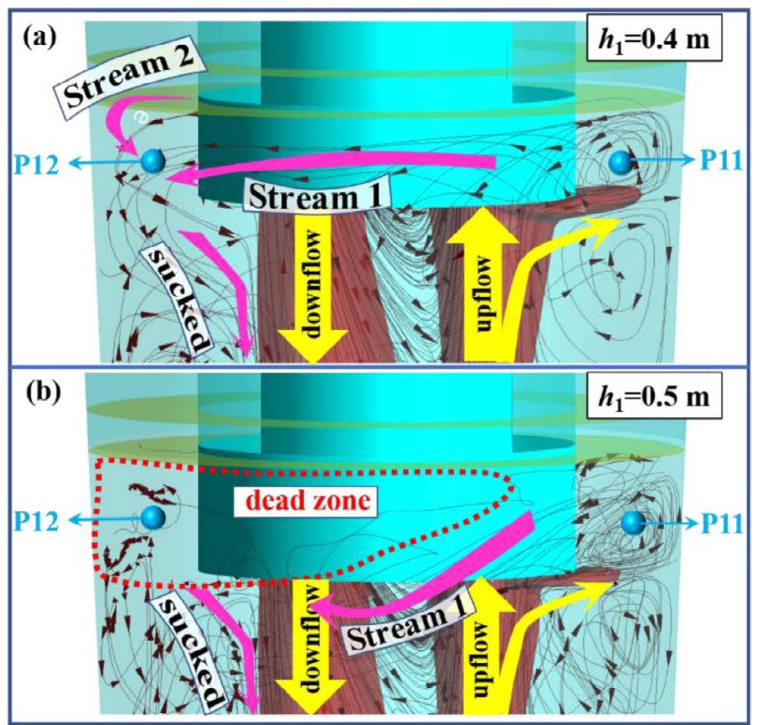

Fig. 16. The shematic diagram of changed flow pattern around the snorkel as the SID exceeds $0.4 \mathrm{~m}$. (Online version in color.)

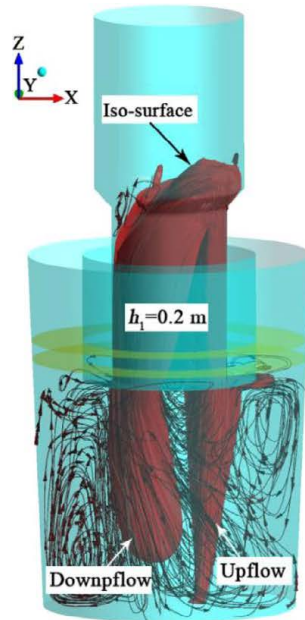

(a)

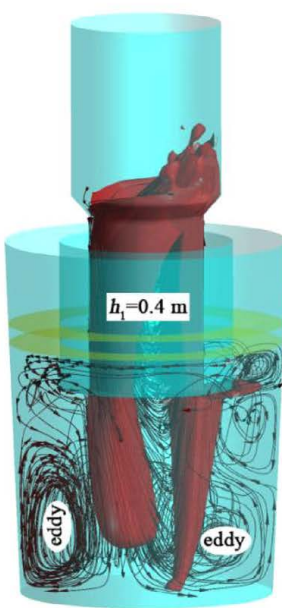

(b)

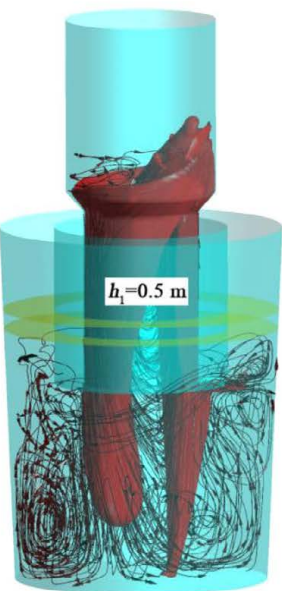

(c)

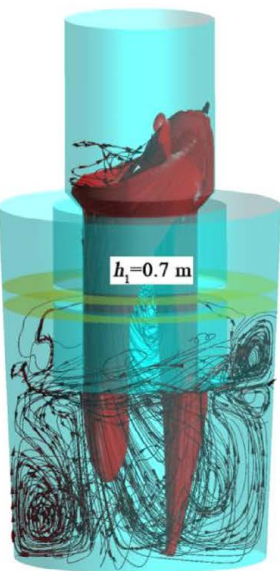

(d)

Fig. 15. 3D streamlines distribution of molten steel and iso-surface of steel velocity $(0.25 \mathrm{~m} / \mathrm{s})$ for different SIDs: (a) 0.2 $\mathrm{m}$, (b) $0.4 \mathrm{~m}$, (c) $0.5 \mathrm{~m}$, (d) $0.7 \mathrm{~m}$. (Online version in color.)

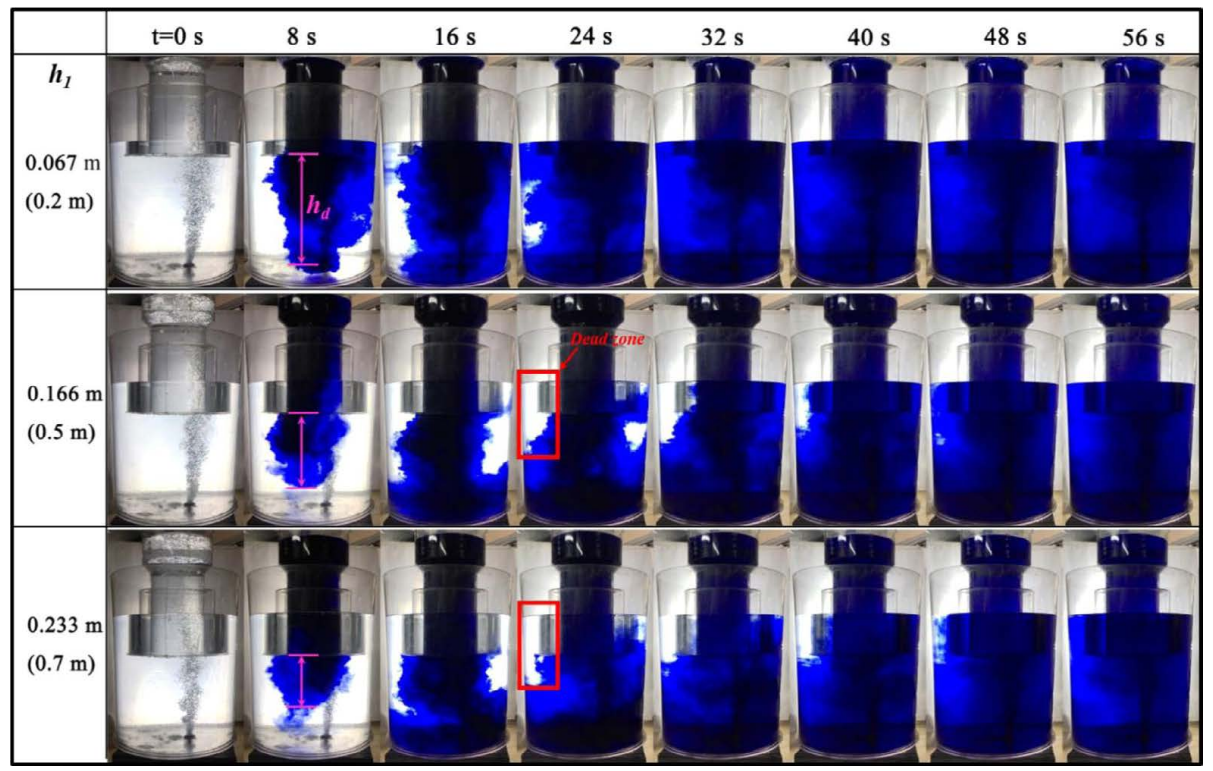

Fig. 17. The front view of the ink spread in the air-water system under different SIDs at gas flow rate of $8 \mathrm{NL} / \mathrm{min}$. (Online version in color.) 


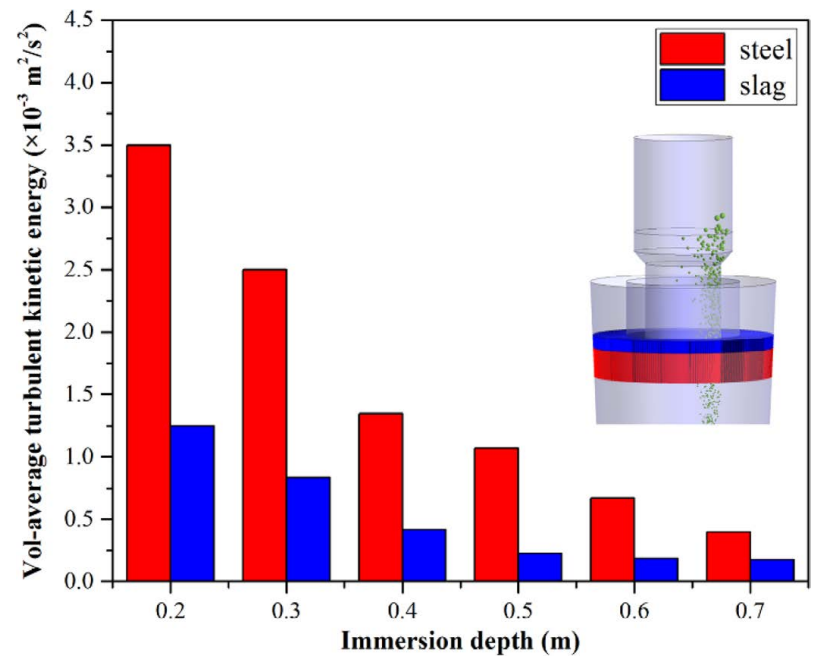

Fig. 18. The effect of SID on turbulent kinetic energy of liquid steel and slag layer around the snorkel. (Online version in color.)

$t=8 \mathrm{~s}$ moment. This phenomenon indicates that the velocity of downflow at the exit of snorkel is decreased with the increase of SID, and this result is consistent with numerical comparison as presented in Fig. 11.

Actually, the flow of slag layer is associated with the flow of molten steel around the snorkel for SSRF. If the large-scaled dead zone of steel exists around the snorkel, the flow intensity of slag layer is also decreased. As seen in Fig. 18, with the increase of SID, the average turbulent kinetic energy of liquid steel and slag around the snorkel is remarkably declined because of increasing region of dead zone around the snorkel. Besides that, the existence of the dead zone also leads to the inhomogeneous distribution of temperature. Accordingly, there is an increasing possibility of slag skull formation at snorkel refractory, and interfacial reaction of slag/metal could be deteriorated. Therefore, the excessive immersion depth of snorkel should be avoided during the snorkel operation.

On the basis of the comparisons of circulation rate, mixing time, and fluid flow for different SIDs, the maximum value of SID should be controlled below $0.5 \mathrm{~m}$ based on the present conditions. In practice, some unstable factors, such as ladle shaking and strong stirring, may cause severe fluctuation of liquid level in ladle. If the fluctuation range exceeds the depth of snorkel immersed, the slag and top air in the ladle may be sucked into the snorkel, then the circulation is destroyed. Therefore, the minimum SID should also be reasonably controlled to avoid the circulation being destroyed, and the $0.2-0.4 \mathrm{~m}$ is recommended as the reasonable snorkel immersion depth for SSRF refining operation.

\section{Conclusions}

In this study, the multiphase flow and mixing behavior in an industrial SSRF have been simulated. Based on the coupled VOF-DPM model, the effect of the bubble expansion and snorkel immersion depth on the circulation rate, mixing time, and flow field were investigated. The following conclusions are drawn:

(1) Compared with the unexpanded bubble, the expanded bubble contributes a higher circulation rate in SSRF, and induces the greater superficial area of free surface in the vacuum chamber owing to its larger rising velocity.

(2) The circulation rate decreased with the increase of snorkel immersion depth because of the increasing circulation path in snorkel.

(3) The mixing efficiency of whole bath is always determined by the mixing speed of local region, which is located at the periphery of snorkel. The mixing time is increased with the increasing snorkel immersion depth due to the deteriorated flow field around the snorkel.

(4) The scope of dead zone is dramatically extended once the immersion depth is more than $0.4 \mathrm{~m}$, and flow intensity of top slag in ladle is also weakened. The reasonable immersion depth is recommended as $0.2-0.4 \mathrm{~m}$ based on the present ladle scale.

\section{Acknowledgement}

The authors express thanks to the National Natural Science Foundation of China (Grant No. 51674024) for the financial support.

\section{REFERENCES}

1) M. Yano, S. Kitamura, K. Harashima, T. Inomoto, K. Azuma and H. Nagahama: Nippon Steel Tech. Rep., 61 (1994), 15.

2) V. Seshadri, C. A. Silva, I. A. da Silva, G. A. Vargas and P. S. B. Lascosqui: Ironmaking Steelmaking, 33 (2006), 34.

3) S. Kitamura, M. Yano, K. Harashima and N. Tsutsumi: Tetsu-toHagané, 80 (1994), 213 (in Japanese).

4) Y. Kishimoto, K. Yamaguchi, T. Sakuraya and T. Fujii: ISIJ Int., 33 (1993), 391.

5) J. Zhang: Dalian Spec. Steel, 3 (1978), 5 (in Chinese).

6) K. Miyamoto, H. Aoki and S. Kitamura: CAMP-ISIJ, 11 (1998), 756 (in Japanese).

7) H. Aoki, H. Furuta, N. Hirashima and S. Kitamura: CAMP-ISIJ, 11 (1998), 757 (in Japanese).

8) H. Aoki, H. Furuta, K. Fujiwara, K. Yamashita, K. Yonezawa and S. Kitamura: CAMP-ISIJ, 11 (1998), 758 (in Japanese).

9) M. Ohji: ISIJ Int., 40 (2000), 529.

10) S. Kitamura, H. Aoki, K. Miyamoto, H. Furuta, K. Yamashita and K. Yonezawa: ISIJ Int., 40 (2000), 455.

11) M. K. Mondal, N. Maruoka, S. Kitamura, G. S. Gupta, H. Nogami and H. Shibata: Trans. Indian Inst. Met., 65 (2012), 321.

12) X. M. Yang, M. Zhang, F. Wang, J. P. Duan and J. Zhang: Steel Res. Int., 83 (2012), 55.

13) D. Q. Geng, X. Zhang, X. Liu, P. Wang, H. T. Liu, H. M. Chen, C. M. Dai, H. Lei and J. C. He: Steel Res. Int., 86 (2014), 724.

14) H. Aoki, S. Kitamura and K. Miyamoto: Iron Steelmaker, 26 (1999), 17.

15) Z. Qin, M. T. Zhu, G. G. Cheng and J. Zhang: Spec. Steel, 31 (2010), 5 (in Chinese).

16) Q. X. Rui, F. Jiang, Z. Ma, Z. M. You, G. G. Cheng and J. Zhang: Steel Res. Int., 84 (2013), 192.

17) Q. Cao and L. Nastac: JOM, 70 (2018), 2027.

18) G. J. Chen, S. P. He and Y. G. Li: Metall. Mater. Trans. B, 48 (2017), 2176.

19) W. X. Dai, G. G. Cheng, S. J. Li, Y. Huang, G. L. Zhang, Y. L. Qiu and W. F. Zhu: ISIJ Int., 59 (2019), 1214.

20) H. T. Ling, F. Li, L. F. Zhang and A. N. Conejo: Metall. Mater. Trans. B, 47 (2016), 1950.

21) S. T. Johansen and F. Boysan: Metall. Trans. B, 19 (1988), 755.

22) Y. Y. Sheng and G. A. Irons: Metall. Trans. B, 24 (1993), 695.

23) B. E. Launder and D. B. Spalding: Comput. Meth. Appl. Methods Eng., 3 (1974), 269.

24) S. A. Morsi and A. J. Alexander: J. Fluid Mech., 55 (1972), 193

25) H. Ling and L. Zhang: Metall. Mater. Trans. B, 49 (2018), 2709.

26) A. H. Castillejos and J. K. Brimacombe: Metall. Trans. B, 18 (1987), 659.

27) K. Satpathy, K. Velusamy, B. S. V. Patnaik and P. Chellapandi: Int. J. Heat Mass Transf., 60 (2013), 392.

28) V. Seshadri and S. L. de Souza Costa: Trans. Iron Steel Inst. Jpn., 26 (1986), 133.

29) D. Mazumdar and R. I. L. Guthrie: ISIJ Int, 35 (1995), 1.

30) S. Joo and R. I. L. Guthrie: Metall. Trans. B, 23 (1992), 765

31) S. Kim and R. Fruehan: Metall. Trans. B, 18 (1987), 381.

32) D. Mazumdar: Metall. Mater. Trans. B, 33 (2002), 937.

33) L. Zhang and F. Li: JOM, 66 (2014), 1227. 